\title{
A poesia de Ruy Duarte de Carvalho para além de fronteiras
}

\author{
The poetry of Ruy Duarte de Carvalho beyond \\ borders
}

Resumo: Neste trabalho, propomos uma leitura da obra Lavra, de Ruy Duarte de Carvalho, discutindo como o escritor faz da poesia lugar de passagem para o reencontro do sujeito com a palavra primordial. Consideramos o autor um poeta viajante, que revisitou o sul angolano e tradições orais da região, promovendo, em seus poemas, travessias e atravessamentos espaciais, culturais e linguísticos.

Palavras-chave: Poesia angolana, Ruy Duarte de Carvalho, travessias.

Abstract: In this paper, we propose a reading of the book Lavra, of Ruy Duarte de Carvalho, discussing how the writer making poetry a path for the union of the subject and the primordial word. We consider the author a traveling poet, who revisited the Angolan south and oral traditions of the region, promoting in their poems, journeys and spatial, cultural and linguistic crossings.

Keywords: Angolan poetry, Ruy Duarte de Carvalho, crossings.

* UNIABEU - Centro Universitário 
...porque toda literatura tenha talvez que abrir-se sempre ao que há para além, à aventura e ao mundo e porque escrever é sempre partir...

Ruy Duarte de Carvalho

iagem e literatura são experiências quase inseparáveis. O lugar do escritor é em todos os lugares. Para além de fronteiras físicas ou estéticas, ele está em eterna busca, aberto a ilimitadas experimentações. Mas se esta é condição de muitos autores, para Ruy Duarte de Carvalho a convivência entre o escritor e o antropólogo fortaleceu o potencial criativo de sua obra, com um sujeito em constante deslocamento. Neste sempre partir, o viajante construiu um percurso singular, com seus temas e obsessões mais caros: o sul angolano, a tradição oral, os povos pastores e o deserto.

Tomamos a poética de Ruy Duarte de Carvalho justamente a partir das múltiplas vozes encenadas por um sujeito que, muitas vezes, se confunde com o autor. Carvalho foi um "nómada no deserto" (AGUALUSA, 1996: 48) e através de suas deambulações etnográficas problematizou o fazer literário e reencenou uma geografia situada ao sul, promovendo uma reflexão sobre o lugar de Angola no mundo contemporâneo. Na poesia, conta sua própria experiência e observa as experiências alheias para contá-las à sua maneira. Sua proposta seria a de que "literatura e viagem se conjugassem em aventura experimentada tanto em extensão como em profundidade para ser então vivida como exaltação e narrada depois como a estória verdadeira de uma tal vontade" (CARVALHO, 2008: 122).

A reunião de sua viagem poética está na obra Lavra (2005). Em primeiro lugar, o ato de lavrar, cultivar a terra, é simbolicamente sagrado, pois estabelece uma ligação transcendente do homem com a terra e o céu. Preparar o solo, plantar e colher compõem um ciclo de fertilidade, de gestação do alimento do corpo e, por consequência, do espírito. $\mathrm{O}$ ato de escrever, por sua vez, pode ser comparado à lavra, na medida em que, ao selecionar as palavras que irão compor o poema, preparando assim o solo da folha em branco, os poetas ensejam coIher imagens plurissignificativas, capazes de reconfigurar a realidade. A poesia é, sobretudo, tempo, que se renova a cada ciclo e faz germinar novas ideias e percepções, como em qualquer lavoura.

Desse modo, Lavra reforça a leitura da "militância pela terra" ou da "educação pela terra" feita por críticos como Cláudia Márcia Rocha (2000) e Rita Chaves 
(2007), mas também confirma o trabalho de depuração estética realizado pelo autor. Os dez livros, nove deles publicados separadamente, são organizados não apenas cronologicamente, mas revistos em seus aspectos, principalmente, semânticos, e formam um conjunto de experiências de geografias e de idades.

Em Das decisões da idade, por exemplo, além de modificar o título original A decisão da idade (1976) -, relativizando tempo e espaço, o poeta reorganiza textos e poemas, como fez com os materiais de expressão oral que manuseou. Na introdução ao livro, afirma: "À vaga geografia das ausências imponho uma paisagem / reassumida, renovada de ardor e nitidez amável" (2005: 57). Na sequência, nos apresenta poemas que problematizam o tempo e o espaço, com destaque para as paisagens do sul angolano, versadas desde o seu primeiro livro. A última estrofe do poema "Estas baías" aponta as direções:

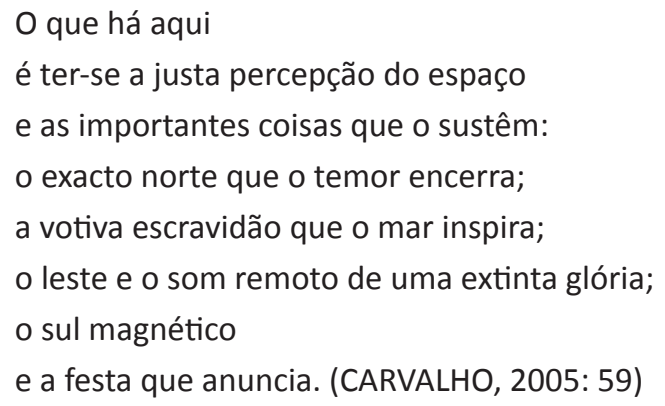

O sul, portanto, é o lugar do magnetismo, das experiências totalizantes e simbólicas que se quer reassumir e renovar. Esta "votação ao sul", para usarmos um verso de Chão de oferta (CARVALHO, 2005: 51), dimensiona toda sua produção artística e intelectual. $O$ escritor ofertou a africanos e a não-africanos um chão rico em saberes "outros", veredas, via de regra, desconhecidas ou ignoradas pelo cenário global ocidentalizado, a fim de propor também a desconstrução do alicerce de muitos papéis neocoloniais.

Novos olhares são de fato reivindicados. Na obra do autor, estão evidentes marcas das travessias por uma diversidade de paisagens culturais, com a proposta de nova leitura de todo um imaginário sobre o continente africano. Em "Venho de um sul", poema dos mais emblemáticos em sua obra inaugural, anuncia o lugar de onde vem, cujo "tempo circular" reatualiza, por meio da palavra, a própria construção do homem e do mundo, em confronto com o tempo regula- 
dor de hegemonias de "um norte" a Ocidente.

Eu vim ao leste
dimensionar a noite
em gestos largos
que inventei no sul
pastoreando mulolas e anharas
claras
como coxas recordadas em maio.

Venho de um sul

medido claramente

em transparência de água fresca da manhã.

De um tempo circular

liberto de estações.

De uma nação de corpos transumantes

confundidos

na cor da crosta acúlea

de um negro chão elaborado em brasa. (CARVALHO, 2005: 35)

O ritmo do poema, gerado a partir de recursos como o uso de aliterações e assonâncias, entre elas "leste / largos; mulolas e anharas / claras; transumantes / confundidos; cor da crosta acúlea", e da entonação, com a alternância de sílabas graves e agudas, como no verso "em transparência de água fresca da manhã" (CARVALHO, 2005: 35), revela o caráter temporal e cíclico do texto. A poesia é, ela própria, "de um tempo circular / liberto de estações" (Idem, p. 35), quer dizer, o tempo de um eterno retorno do ritmo, com o sujeito abrindo-se a experiências de sentido.

A voz lírica sugere a expansão do tempo e do espaço, encontrando-se a leste para "dimensionar a noite / em gestos largos" (CARVALHO, 2005: 35). Viajar a impulsiona a olhar para dentro a partir da experiência dinâmica do ir e vir, como fez Duarte em vida, em consonância com os "corpos transumantes" da nação angolana, em especial, os do sul, lugar de invenção de sua arte e de reinvenção de paradigmas. Em certa medida, a localização apresentada no poema sacraliza o "negro chão" dos africanos, pois este é impregnado de ser, refúgio de forças 
capazes de diferenciá-lo e de conferir-Ihe significado e valor. "Elaborado em brasa", o chão resiste ao tempo e aponta a construção de um novo começo, inclusive para Angola, prestes a conquistar sua independência, quando da escrita do texto.

A partir de então, Ruy Duarte se lança com força sobre o potencial do discurso poético. Trabalhando simultaneamente diferentes linguagens, como a épica, a teatral, a cinematográfica, a plástica, a fotográfica, a narrativa, a referencial, a descritiva, a ensaística e outras, leva-nos a refletir sobre o mosaico que se vai construindo em torno de sua moderna poesia. A começar pelo papel do sujeito lírico, que se constrói dentro e fora do poema, já que, muitas vezes, encontramos aí importantes traços biobibliográficos do escritor. O poema "Tempo em ausência", dividido em dois momentos, um em prosa e outro em verso, que abre o livro A decisão da idade, de 1976, nos oferece um exemplo da busca do sujeito pela palavra e da palavra pela imagem. Vejamos uma passagem do primeiro momento:

Vou caminhar em frente até que atinja o mar. Não este mar que vejo à retaguarda, donde nos vem a brisa laminar das tardes de setembro, mentor do céu de bruma que nos maninha o chão.

Eu vou seguir em frente e ultrapassar o paredão das serras, a cortina das águas que na distância acende a redobrada angústia de uma possível esperança. (Grávida brecha no vapor salgado, que permitisse o derramar das águas na raiz dos pastos, na porcelana vítrea das lagoas, na sede solta dos areais das dambas!...)

Vou caminhar em frente e procurar o espelho de outras águas, como se fosse a última estação e eu nunca mais morresse ao pôr do Sol no ventre insaciável das viagens.

Eu tenho à minha frente os continentes todos, a dimensão soberba de oceanos dados às mãos do meu vigor e audácia, a vastidão do céu e os magnos horizontes da loucura, a clareira das praças e o sexo aberto das multidões estrangeiras, os reinos do passado e o estimulante sobressalto da penetração possível das idades. Dentro de mim, uma saudade eterna de sorrisos, uma urgência vital de retratar imagens, de destinar-me às chamas da minha combustão. (CARVALHO, 2005: 55.)

Aqui, a poesia é expressa em prosa, ou seja, é empregada a linha contínua da página. Ao todo, o momento inicial do poema é dividido em dez parágrafos, 
havendo um espaço a mais entre o terceiro e o quarto, o quinto e o sexto, e o oitavo e o nono. Levando em conta esta organização, poderíamos dizer que a separação dos parágrafos indica uma sequência de quatro "estrofes". Nas duas primeiras, transcritas acima, observamos a composição da frase em segmentos que lembram a cadência do verso e são impregnados de lirismo. Cada parágrafo parece explodir em um jato, com um ritmo que vai reunindo harmonicamente os membros do período sintático.

A linguagem polissêmica do poético é latente, capaz de exprimir a pluralidade de sensações, um somatório do confronto entre elementos concretos e inquietações subjetivas. A musicalidade, especialmente no uso de aliterações e assonâncias, e a metaforização intuitiva aproximam o poema de traços simbolistas, como em "(Grávida brecha no vapor salgado, que permitisse o derramar das águas na raiz dos pastos, na porcelana vítrea das lagoas, na sede solta dos areais das dambas!...)" ou em "o estimulante sobressalto da penetração possível das idades". As frases musicais acabam por ter primazia sobre o sentido, uma vez que o que está em jogo é a fruição poética, podendo o leitor ficar mais com a sensação do que exatamente com o conteúdo.

Além do uso de imagens plurissignificativas, o detalhamento descritivo e a plasticidade, como se o poeta desenhasse duas visões - a do lugar que se pretende ir, representado a partir do mar e de toda a natureza circundante, e a do imaginário, figurada por "uma urgência vital de retratar imagens, de destinar-me às chamas da minha combustão" (CARVALHO, 2005: 55) -, ao contrário do que possa parecer, revelam uma noção pouco precisa do espaço e do tempo, outra característica singular do gênero lírico. Mesmo que as deambulações etnográficas do autor nos dê pistas sobre o espaço, este ainda se mostra nebuloso para o leitor. De que mares está falando o sujeito? O leitor atento e abastecido de referentes pode identificar ao menos dois: o oceano Atlântico "à retaguarda", pois seria "mentor do céu de bruma que nos maninha o chão" (Idem, p. 55), ou seja, atrás da história dos angolanos estão os portugueses e a colonização instituída no país, que "maninhou" o chão, quer dizer, deixou "sem cultura" a terra; e o mesmo Atlântico a sul, para além do "paredão das serras" (Idem, p. 55) e margeando o deserto do Namibe. Contudo, o espaço ainda é volúvel, por ser também o lugar do "eu". Segundo Massaud Moisés, no gênero prosa poética, "a geografia do "eu" não conhece fronteiras" (2012: 574). Não é à toa que o tempo dramatizado está "em ausência", com o sujeito em suspensão, preparando-se 
internamente para mais uma viagem.

Todos esses elementos configuram não só o poema, mas a tentativa de exploração do potencial da poesia por Carvalho. No uso da linguagem em prosa, a estudiosa francesa Susanne Bernard, aqui citada a partir de Moisés, recorda que "na base de toda tentativa de poema em prosa, há uma vontade de encontrar uma forma nova, individual, ao mesmo tempo anárquica em relação às formas estabelecidas e artísticas em sua organização" (apud: MOISÉS, 2012: 580). É exatamente esta a proposta de Carvalho: anarquizar a forma e o conteúdo do poema para expandir os sentidos da poesia em outras vozes. Para a pesquisadora Rita Chaves,

Livre, seu verso trabalha na concepção de uma convenção poética que nasce precisamente da comunhão da poesia com a terra e com a consagração de um universo que ele escolheu como o espaço privilegiado para demarcar a sua viagem. Poeta transumante, Ruy Duarte pastoreia as palavras e, com elas, propõe novos sentidos que o leitor pode (e deve) acordar. (CHAVES, 2005: 125)

O autorretrato tracejado em 1982 e incluído em Lavra paralela, de 1987, é mais uma ilustração do "poeta transumante", pastor de palavras, com cara de boi e corpo de humano, assemelhando-se, inclusive, ao Minotauro no meio do deserto-labirinto. Se o poema em prosa, a poesia concreta ou a épica estão presentes nos dois primeiros livros do autor, nos seguintes, eles se somam à inovação estética buscada na incorporação de desenhos próprios e de outros artistas, além da constante rearrumação dos versos na página, da seleção distinta do léxico, de narrativas poéticas e de toda uma gama de gêneros reassumidos liricamente.

Em Exercícios de crueldade, de 1978, a memória da guerra é tema em evidência nos poemas, carregados de um lirismo associado ao sentimento de dor causado pela crueldade como ato e como dureza de um destino. Em entrevista a Michel Laban, Carvalho declarou ser este "um livro que não poderia ter sido escrito fora de Angola. E, no entanto, muito pouco, nele, se refere objetivamente a Angola" (LABAN, 1991: 704), sendo essa a sua maneira de "estar na poesia" (Idem, p. 704). A matéria de fato tende ao global, como se afirma toda grande poesia. As guerras referidas neste seu exercício poético são muitas, incluindo as lutas internas do sujeito, na sua "vocação de ausência", cujo silêncio é uma 
respiração no tempo à espera da voz. No poema "Dedicatória", encontramos um belo exemplo dessa experiência de sentido:

Era janeiro e a chuva não caía. Mas era um mês batido por torrentes e se eu fizesse um esforço para fechar os olhos reconhecia logo os horizontes que o corpo uma vez mais queria rever para consultar-se, humilde. Depois partir talvez, se perdurasse a vocação da ausência.

A chuva não caía e eu aspirava aos cheiros de uma terra negra que a idade enriquecera e que só eu sabia. Era uma terra exacta para entender agora, cavada fundo na aridez dos livros, isto é, das viagens, isto é, das leituras, isto é, das decisões da idade.

Muita gente morrera, no entanto, rodeada pela maior das discrições. Era uma coisa que eu previra algures e pela qual chorara, muito novo ainda, a despedir-me já e no entanto belo, extuante de vigor e de intenções de entrega. Era o futuro aberto à presciência incauta. Era um choro prematuro e fecundante.

Havia um texto para encerrar um livro e havia um livro para encerrar um tempo. E eu precisava de um lugar de noite, de um tempo simultâneo sobreposto ao meu, de uma matriz de areia aonde o verbo se ajustasse ao vento para esculpir no flanco das falésias um texto de silêncios que excedesse os livros. Um texto assim, se o conseguisse agora, seria para entregá-lo a quem me escuta e a quem repito, para ocultar o medo:

É um lugar nas dobras do deserto, um rumor de aluviões inesperados, um abrigo sonegado à ventania: é um lugar no Giraul de Cima. (CARVALHO, 2005: 127)

O poema apresenta quatro movimentos, em mais uma mistura da prosa e do verso: no primeiro, composto por dois parágrafos, sobressaem elementos da paisagem eleita na trajetória do escritor, a "terra negra" a que se propôs "entender" através da "aridez dos livros, isto é, das viagens, isto é, das leituras, isto é, das decisões da idade" (CARVALHO, 2005: 127). A ressonância da expressão explicativa "isto é" dá o grau de equivalência entre as escritas, as viagens, as leituras da voz, da letra e do mundo, e do tempo; no segundo, a morte e a dor tomam a cena na visão particular de uma guerra "rodeada pela maior das discrições", em crítica direta a atos de crueldade estrategicamente ignorados pela 
comunidade internacional, tantas vezes ainda repetidos quando os interesses econômicos se sobrepõem aos direitos humanos; no terceiro, o caráter metalinguístico do texto nos dá pistas sobre a obra de um poeta em eterna busca pela palavra capaz de inquietar os alicerces do mundo. Por isso, precisa retornar ao seu lugar, indicado em verso, já no quarto movimento, "um lugar nas dobras do deserto".

Assim, a "Dedicatória" é para oferecer ao outro esse livro que é a palavra do poeta, a palavra original, desviada pelos "exercícios de crueldade" praticados pelo homem de uma modernidade autodestrutiva, no seu impulso em "explorar pessoas, tratando-as simplesmente como meios ou (em termos mais econômicos do que morais) mercadorias" (BERMAN, 1986: 97).

A quarta publicação de Carvalho é datada de 1979 e a Huíla é, como declarou o poeta, "mãe desse poema [Encontrarás sinais pelo caminho... sinais misteriosos, já se vê...] e de todos os que aparecem nos Sinais" (LABAN, 1991: 706). No seu processo de criação, afirma ter guardado durante anos a frase inicial do poema e de onde resgata o título do livro, para trabalhá-la em uma explosão de imagens quando se deu conta de ter amadurecido "a ciência que guardava" (Idem, p. 706) do lugar. Incluindo desenhos, um poema que mistura linguagem cinematográfica, ora em prosa ora em verso trabalhado visualmente na página, além de uma sequência de poemas chamados "Estórias", motivados por um fragmento de conto nyaneka retirado de "Cinquenta contos bantos do sudoeste de Angola", de Carlos Estermann, o livro revela o caminho que Duarte passará a percorrer com maior fôlego nos anos seguintes, em busca dos sinais misteriosos da terra e da reencenação literária desses sinais a partir de linguagens que se entrecruzam e se pluralizam a cada novo olhar para o sul.

Na Lavra de Ruy Duarte encontramos uma poética permeada também pela lavra alheia, textos orais de diferentes autorias populares. A escrita do poeta nasce de uma reescrita, de uma releitura da língua materna, em que se cruzam aspectos da tradição oral do sul angolano. Pensa a língua portuguesa neste espaço africano, apreendendo-a de uma perspectiva outra, em um entrelugar que desliza entre a fala e a escrita. E ao articular literariamente a modalidade dominante de oralidade, cuida da memória dos muitos grupos identitários angolanos.

Em Ondula, savana branca, obra publicada em 1982 e que na poesia reunida intitula-se também "Da lavra alheia I", Carvalho faz um de seus mais profícuos trabalhos com expressões orais africanas. Em nota introdutória, o autor escla- 
rece que o livro é fruto do tratamento dado a diversas fontes orais e que foi organizado em três partes, segundo objetivos determinados de adaptação dos textos para a poesia. No primeiro capítulo, intitulado "Versões", adaptou poemas versados em língua francesa e em língua inglesa, publicados em diferentes obras. No segundo capítulo, chamado "Derivações", interveio em materiais a fim de configurá-los como poesia. Por fim, em "Reconversões", transformou em linguagem poética o texto iniciático dos pastores peul (fulas), no intuito de também viabilizar o contato de leitores de poesia com recolhas etnográficas. Ao final, indica as fontes e / ou as referências utilizadas em cada uma das composições e escreve notas explicativas que considera relevantes para uma leitura contextualizada dos poemas.

Uma pergunta de imediato nos instiga, quando pensamos na relação poesia e sagrado: por que Carvalho fez poesia com as fontes orais exploradas? Por que escolheu inicialmente o gênero poema?

As motivações do poeta podem ter sido inúmeras e de ordens diversas. A Michel Laban declarou que a produção de poesia "não pode ser senão o resultado da emergência e do curso da própria poesia" (LABAN, 1991: 700) e que "há temas e matérias que não podem ser tratados em poesia, enquanto há outros que não podem senão em poesia" (Idem, ibid.). Acentua que o mesmo corpus de referências pode ser manejado de várias maneiras, porém, a questão seria saber que materiais e que modalidades estaria apto a aproveitar e a praticar. Ora, por mais que Ruy Duarte tenha substituído fortemente a poesia pela prosa no seu percurso literário, os "signos em rotação", para usar a expressão de Octavio Paz, da sua poesia parecem ganhar a dimensão da "palavra anterior", que, na confluência dos tempos, aproxima os homens dos homens, tirando do esquecimento o sentido sagrado da própria existência.

Ao traduzir os materiais recolhidos em poemas, o autor aproxima a palavra de cânticos, provérbios, mitos, rituais, ensinamentos e outros elementos pertencentes ao lugar sagrado que a poesia ocupa na escrita literária. A relação do leitor com tais materiais em uma escrita com função predominantemente referencial ou didática, por exemplo, não seria da mesma ordem.

Entre os textos recuperados poeticamente, estão respostas do oráculo de Ifa, porta-voz de divindades cultuadas entre os yorubas, profecias em kwanyama, o ensinamento oral do Koré, praticado pelos bambaras, o texto iniciático dos pastores peul, entre outros. O universo do sagrado é patente no livro e a poesia 
é todo um rito de sonoridades comungadas na escrita, como podemos constatar no poema "profecia de Muselenga":

Uedyulu!

Eu já não vejo o gado do rei

eu já não vejo o gado dos grandes!

Apenas de Naminda, e de si só

eu vejo o gado

em Osihedi.

Nas terras de Hayndongo

não vejo senão

as casas dos brancos

de um branco tão branco como o da farinha.

Acaba-se o mundo, acaba de todo!

O rei partirá para o ombala da rã

debaixo do chão

e eu próprio me vou

abrigar no túmulo:

ultrajei o rei. (CARVALHO, 2005: 174-175)

O ritmo do poema, gerado a partir do uso de repetições, de uma cadência métrica, da recorrência a figuras fonéticas e de uma seleção vocabular minuciosa, dá o tom da previsão profética relacionada às riquezas provenientes do gado e às relações entre rei e súdito.

Já em Lavra paralela, de 1987, como o próprio título sugere, são inúmeros os paralelos costurados nos textos, em especial entre a antropologia e a literatura, as fontes etnográficas e a produção poética. O sujeito permanece à espreita, investindo-se de e na paisagem, com o intuito de dizer a seu modo o vivido e o visto em intercâmbios com o outro.

Como se fosse preciso persistir no apuro

para merecer a mão que se pressente.

Bastava acenar garantiria a fala

essa afeição segura de intenções cruzadas:

o contorno das trocas. (CARVALHO, 2005: 267) 
Com Observação direta, a lavra alheia pesquisada pelo poeta antropólogo ganha nova ressonância, ampliando, através da letra, outras vozes pertencentes ao mundo da sabedoria angolana. Aqui, Ruy Duarte trabalha esteticamente com extrações nyaneka, kwanyama, kuvale, além de recolhas pessoais. São provérbios, canções pastoris, memórias, hinos, salmos e preces clânicas resultantes de um contexto temático ligado a tradições orais africanas e de um exercício de tramas dos recursos da linguagem. Vejamos um poema de "extracção kuvale: das leituras da carne":

1. o traço. assim. luvinda é o caminho da chuva

nenhum traço .esses da inveja. afinal. OS óleos disse: essa parte no rio. ..̀े nossa volta, os rios. apareceu aí.. e agora ele disse: os rios. o leite e os rios.

(CARVALHO, 2005: 342)

Os pontilhamentos marcam o tempo da fala, entrecortada, por vezes enigmática, mas também o tempo / traço da chuva a abastecer rios e terras e todo o movimento transumante dos pastores kuvale. Esses mesmos pontos prolongados podem ser encontrados em vários momentos nas obras de Carvalho, aparecendo, por exemplo, insistentemente, no último livro do escritor, $A$ terceira metade, publicado em 2009, romance tomado por leituras intertextuais do seu próprio percurso literário e acadêmico, em vigoroso diálogo com a poesia.

Antes de Lavra paralela (1987) e Observação direta (2000), vieram Hábito da terra (1988) e Ordem de esquecimento (1997). Este retoma um dos temas caros à poesia, o do desconcerto do mundo, para lembrarmos também o clássico camoniano. Os poemas, ao contrário do que possam sugerir, tiram do esquecimento tormentos, desassossegos e alguma história / estória angolana, como a memória da guerra ou a difícil circunstância da migração de povos. 0 poema de abertura, que dá título ao livro, é composto por trinta e oito momentos / poemas, com extensão e linguagens diversas, como podemos flagrar em 5, 7 e 9: 
de alguma forma no flanco a facada... (CARVALHO, 2005: 287)

7

DIÁLOGO

:... seria a face da esfinge... de perfil?

: ... não, frontal. (CARVALHO, 2005: 288)

9

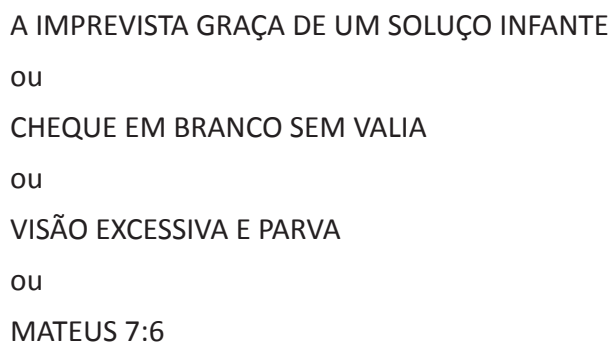

Alguma dor cortante, violina, um gume, acorda uma saudade do que nunca foi, inventa um tempo afável, o da distância aberta no olhar da tarde que se debruça sobre o meu deleite, sobre a surpresa de a achar suspensa no limiar daquilo que previa, e assim já a sabia, sem saber de ti.

(...) (CARVALHO, 2005: 288)

A contenção e a sonoridade de um único verso em 5 , a pontuação e o jogo semântico do diálogo sintético em 7, mais a pluralidade da epígrafe-título em 9, somados à prosa poética, dão a dimensão da poesia como a terceira margem da linguagem e, consequentemente, do humano. A dor "violina" a que se refere o sujeito, que "acorda uma saudade do que nunca foi", pode ser lida como imagem da própria poesia, que "revela este mundo; cria outro" (PAZ, 1982: 15).

Revelar e criar mundos é próprio da literatura, assim como o é o "hábito da terra". Segundo Claudia Marcia Rocha, em Hábito da terra "a escrita-terra burila o gesto e a forma" (2000: 326). Na obra, Ruy Duarte explora elementos da tradição oral, como provérbios e citações, relacionando o antigo e o novo de maneira a entrelaçar esteticamente tempos e espaços. "Não há lugar achado / sem lugar perdido. / Casam-se além, as falas de um lugar, / no encontro da memória / com a matriz." (CARVALHO, 2005: 231), diz o sujeito em um dos poemas. Ou seja, trata-se de uma questão, de novo, de apreensão de sentidos. Para Carvalho, a proposta é de: 
(...) encontrar, na elaboração dos textos e para quem labora no registo das expressões escritas, uma forma que se atrevesse a visar correspondências com outros exercícios da retenção da palavra, por outros meios mnemônicos, como os récits ritmados que recorrem às técnicas da repetição e dos paralelismos comuns às expressões orais estabelecidas e sedimentadas, embora sempre abertas à invenção que os narradores thes imprimem, porque a sua maneira pessoal de contar ou as audiências que os ouvem a isso os conduzem. ou da necessidade de encontrar as palavras certas para apreender, para ter alguma noção daquilo que o espectáculo da via oferecia para ver. (CARVALHO, 2008: 17)

Por isso, o poeta reescreve e rediz de maneiras diferentes sua "arte poética" ou sua "aprendizagem do dizer festivo" (CARVALHO, 2005: 229-233). Os quatro poemas do primeiro momento da obra se autorreferenciam, dialogam sobre o processo de representação da arte, em espelhamentos e refrações de experiências líricas, como vemos nos fragmentos a seguir:

1.

Atento, desde sempre, às falas do lugar, nada sei dos sinais se os não confirmo no encontro da memória com a matriz, quando a carência impõe esforços de equilíbrio não entre o corpo e as formas que o sustêm mas entre as margens de uma paragem breve. Registo acasos que desmentem datas e só as não confundem porque é mesmo assim: regularmente e a confirmar a história. Que se constrói, a vida, um texto? (...)

Um texto é como um esforço de existir. A intenção de lado, uma moral herdada. Do outro lado o curso das palavras, a esteira do seu eco, os sons e os gestos seguidos uns aos outros, um som que pede um som e essa resposta é já um bolbo de emoção autônoma, para florir madura, à revelia da intenção primeira. (CARVALHO, 2005: 229. grifos nossos)

2.

Que se constrói? Um texto ou um percurso? A intenção de um lado, resposta vaga, moral herdada. Do outro lado o curso da palavra, da resposta, o som e o gesto seguidos um ao outro, um som que aponta a um gesto que exige um som liberto, e o acto assim é já um bolbo de intenção segura, à revelia da emoção primeira. (CARVALHO, 2005: 230. grifos nossos) 
4.

A intenção de um lado

uma proposta vaga

uma moral herdada.

Do outro lado

o curso das palavras

os sons

e os gestos

seguidos uns dos outros

um som

que obriga a um gesto

e gera um som liberto

que o confirma.

Um bolbo de emoção

autônomo de força para florir

à revelia da intenção primeira. (CARVALHO, 2005: 232. grifos nossos)

O poeta brinca com as formas, com as palavras e com as semânticas nos textos, como convém à criação poética, para mostrar, entre outras coisas, que a poiésis, assim como a pensou Aristóteles, é encenação e o poeta é um dramaturgo que compõe dinamicamente quantas peças quiser e como seu potencial inventivo permitir.

Por fim, o Livro $X$ - Diário, de Lavra, traz uma sequência de "poemas em viagem". O sujeito dos poemas é um viajante, que procura incessantemente reconstituir, com o olhar, a paisagem, na busca pela palavra que dê conta de nomeá-la. Seu percurso é geográfico, indo de "1. moçâmedes", "2. yona", "3. maihawa", "4. tyakutu”, "5. vitivi (I)", “6. malola", "7. vitivi (II)”, "8. lute”, "9. kairofa", até chegar ao "10. deserto", mas é, sobretudo, um percurso discursivo, inscrito neste Diário e inserido no labirinto da sua obra como um todo. As estratégias do roteiro de viagem e do diário aparecem na maioria de seus livros em prosa também, entre eles o fundamental Vou lá visitar pastores (1999) e o romance Os papéis do inglês (2000).

Em "3. maihawa", em um dos onze momentos aqui registrados poeticamente, Carvalho inclui um poema concreto, ou poema visual, em mais uma ruptura com a unidade formal do verso, dispondo espacialmente os vocábulos a fim de 
ajustá-los ao desenho que complementa o sentido da formação do arco-íris, um fenômeno óptico que surge em razão das cores irradiadas pela luz solar:

$/ /$

havia um magnífico arco-íris a nordeste/

(é chuva que bate na serra/

mas por enquanto/

não passa de lá)/

1
$/$
$/$$\triangle \triangle$ (CARVALHO, 2005: 381)

Há, portanto, nos poemas de Diário, mais uma vez, uma diluição das fronteiras entre os gêneros, com a poesia misturando-se à prosa, dando lugar, inclusive, a apontamentos para um suposto romance. Em vários momentos, o sujeito quebra um verso, uma estrofe ou um parágrafo para "anotar no diário" trechos indicados, por ele, como sendo "para o romance" (2005: 378; 379; 386; 395). Tais apontamentos são mais algumas das marcas intertextuais que os textos de Carvalho apresentam entre si. Toda a obra do escritor é recortada por referências a outras de suas falas, por caminhos discursivos que se refazem no tempo e no espaço da página e do deserto atravessado constantemente.

Dessa forma, podemos dizer que a poética de Ruy Duarte de Carvalho apresenta-se como um discurso em ascensão, em que o poeta viajante gradativamente incorpora e ressignifica elementos simbólicos do universo angolano, encenando manifestações do sagrado presentes no cotidiano, experiências do próprio sujeito e da linguagem, com o objetivo de constituir uma memória coletiva do grupo. 


\section{Referências}

AGUALUSA, José Eduardo. O nómado no deserto. Entrevista com Ruy Duarte de CarvaIho. In: Revista Ler - livros e leitores, Lisboa, n. 35, p. 48-51, 1996.

BERMAN, Marshall. Tudo que é sólido desmancha no ar: a aventura da modernidade. Trad. Carlos Felipe Moisés, Ana Maria L. Ioriatti. São Paulo: Companhia das Letras, 1986.

CARVALHO, Ruy Duarte de. Vou lá visitar pastores. Lisboa: Cotovia, 1999.

CARVALHO, Ruy Duarte de. Os papéis do inglês. Lisboa: Cotovia, 2000. . Lavra: poesia reunida 1970-2000. Lisboa: Cotovia, 2005. . A câmara, a escrita e a coisa dita... fitas, textos e pales-

tras. Lisboa: Edições Cotovia, 2008. . A terceira metade. Lisboa: Cotovia, 2009.

CHAVES, Rita. A poética de Ruy Duarte de Carvalho: memória e cumplicidade. In: CHAVES, Rita. Angola e Moçambique: experiência colonial e territórios literários. São Paulo: Ateliê Editorial, 2005, p. 121-136.

. Ruy Duarte de Carvalho: a educação pela terra. In: CHAVES, Rita, MACÊDO, Tânia, VECCHIA, Rejane (orgs.). A kinda e a misanga: encontros brasileiros com a literatura angolana. São Paulo: Cultura Acadêmica; Luanda: Nizla, 2007, p. 109-116. LABAN, Michel. Encontro com Ruy Duarte de Carvalho. In: Angola: encontro com escritores. vol. 2. Porto: Fundação Eng. António de Almeida, 1991, p. 695-708.

MOISÉS, Massaud. A criação literária. São Paulo: Cultrix, 2012.

PAZ, Octavio. O arco e a lira. Trad. Olga Savary. Rio de Janeiro: Nova Fronteira, 1982.

PAZ, Octavio. Signos em rotação. Trad. Sebastião Uchoa Leite. São Paulo: Perspectiva, 1996.

ROCHA, Cláudia Márcia. Ruy Duarte de Carvalho: a construção do texto e de (muitos) percursos. In: SALGADO, Maria Teresa, SEPÚLVEDA, Maria do Carmo (org.). África \& Brasil: letras em laços. Rio de Janeiro: Atlântica, 2000, p. 321-328. 